\title{
tPA Contributes To Impairment of ATP and Ca Sensitive K Channel Mediated Cerebrovasodilation After Hypoxia/Ischemia Through Upregulation of ERK MAPK
}

\author{
William M. Armstead ${ }^{1,2}$, John Riley ${ }^{1}$, Douglas B. Cines. ${ }^{3}$, and Abd Al-Roof Higazi ${ }^{3,4}$ \\ ${ }^{1}$ Department of Anesthesiology and Critical Care, University of Pennsylvania, Philadelphia, PA \\ 19104 \\ ${ }^{2}$ Department of Pharmacology, University of Pennsylvania, Philadelphia, PA 19104 \\ ${ }^{3}$ Department of Pathology and Laboratory Medicine, University of Pennsylvania, Philadelphia, PA \\ 19104 \\ ${ }^{4}$ Department of Clinical Biochemistry, Hebrew University-Hadassah Medical School, Jerusalem, \\ Israel
}

\begin{abstract}
The sole FDA approved treatment for acute stroke is tissue type plasminogen activator (tPA). However, tPA potentiates impairment of pial artery dilation in response to hypotension after hypoxia/ischemia (H/I) in pigs. ATP and Ca sensitive K channels (Katp and Kca) are important regulators of cerebrovascular tone and mediate cerebrovasodilation in response to hypotension. Mitogen activated protein kinase (MAPK), a family of at least 3 kinases, ERK, p38 and JNK, is upregulated after $\mathrm{H} / \mathrm{I}$, with the ERK isoform contributing to vasodilator impairment. This study examined the effect of $\mathrm{H} / \mathrm{I}$ on Katp and Kca induced pial artery dilation and the roles of tPA and ERK during/after injury in piglets equipped with a closed cranial window. H/I blunted vasodilation induced by the Katp agonists cromakalim, calcitonin gene related peptide (CGRP) and the Kca agonist NS 1619; the effect of each was exacerbated by tPA. Pre- or post-injury treatment with EEIIMD, a hexapeptide derived from plasminogen activator-1, and ERK antagonist U 0126 prevented Katp and Kca channel agonist induced vasodilator impairment while the inactive analogue EEIIMR had no effect. ERK was upregulated after H/I, which was potentiated by tPA. These data indicate that $\mathrm{H} / \mathrm{I}$ impairs $\mathrm{K}$ channel mediated cerebrovasodilation. tPA augments loss of $\mathrm{K}$ channel function after injury by upregulating ERK. These data suggest that thrombolytic therapy for treatment of CNS ischemic disorders can dysregulate cerebrohemodynamics by impairing cation-mediated control of cerebrovascular tone.
\end{abstract}

\section{Keywords}

cerebral circulation; newborn; plasminogen activators; signal transduction; ischemia

(c) 2010 Elsevier B.V. All rights reserved.

Correspondence: William M. Armstead, Ph.D, Department of Anesthesiology and Critical Care, 3620 Hamilton Walk, JM3, University of Pennsylvania, Philadelphia, PA 19104, (215) 573-3674, Fax: (215) 349-5078, armsteaw @uphs.upenn.edu.

Publisher's Disclaimer: This is a PDF file of an unedited manuscript that has been accepted for publication. As a service to our customers we are providing this early version of the manuscript. The manuscript will undergo copyediting, typesetting, and review of the resulting proof before it is published in its final citable form. Please note that during the production process errors may be discovered which could affect the content, and all legal disclaimers that apply to the journal pertain.

Section: Disease related neuroscience. Theme: Ischemia, developmental disorders 


\section{Introduction}

Tissue plasminogen activator (tPA) is a serine protease that converts plasminogen to the active protease plasmin $(11,15)$. Recombinant tPA is the only FDA approved for stroke (25). However, tPA exhibits deleterious as well as beneficial effects that profoundly constrain its clinical utility. In addition to its salutary role in reperfusion, tPA contributes to excitotoxic neuronal cell death (33) and increases stroke infarct volume in mice (35). We have observed that pre- and post-injury treatment with tPA potentiated hypoxic/ischemic impairment of pial artery dilation in response hypercapnia and hypotension $(5,7)$. In other studies, we have shown that a plasminogen activator derived peptide, EEIIMD, inhibits the binding of tPA and uPA to the low density lipoprotein receptor (LRP) thereby blocking their effect on vascular contractility without inhibiting their fibrinolytic activity $(6,14,31)$. Pre-injury treatment with EEIIMD partially prevented impairment of hypercapnic and hypotensive dilation after cerebral hypoxia/ischemia (5).

Perinatal cerebral hypoxia/ischemia has many causes, unclear pathophysiology, no specific mechanism-related treatment, and poor outcome. Neonatal stroke may occur in as many as 1 in 4000 births (32). In newborns with stroke, complications like hypoxia/ischemia are common (19). Maternal and perinatal coagulopathy predispose to perinatal stroke $(20,26)$, with $30 \%$ of neonatal strokes being due to thrombosis (17). The use of tPA in children has been limited and its benefit remains unclear $(13,24)$. The use of tPA in children is based on the assumption that studies in adults are generalizable (16), but the safety and efficacy of tPA in this setting have yet to be systematically investigated. Indeed, the 2001 workshop report of the National Institute of Neurological Disorders and Stroke noted a deficiency in research in pediatric stroke related to the paucity of animal models and basic research investigation into ischemic disorders of the CNS in the pediatric population (30). A better understanding of cerebral hypoxic/ischemic pathophysiology is needed to develop mechanistically driven therapies.

One contributor to neurological damage after hypoxia/ischemia is thought to be cerebrovascular dysfunction. For example, hypotension leads to loss of cerebrovascular regulation promoting tissue ischemia, while hypercapnia related to respiratory disease and hypoventilation contributes to periventricular leukomalacia in the perinate (34). Using a piglet model, we have shown that pial artery dilation in response to hypotension and hypercapnia is blunted after cerebral hypoxia/ischemia $(23,28,29)$. However, the mechanism underlying loss of compensatory vasodilation and therapeutic avenues to ameliorate its deleterious effects on CNS ischemia remain uncertain.

Relaxation of blood vessels can be mediated by several mechanisms, including cGMP, cAMP, and $\mathrm{K}^{+}$channels (18). Membrane potential of vascular muscle is a major determinant of vascular tone, and activity of $\mathrm{K}^{+}$channels is a major regulator of membrane potential (18). Activation or opening of these channels increases $\mathrm{K}^{+}$efflux, producing hyperpolarization of vascular muscle. Membrane hyperpolarization closes voltagedependent calcium channels and causes relaxation of vascular muscle. Direct measurements of membrane potential and $\mathrm{K}^{+}$current in vitro indicate that several types of $\mathrm{K}^{+}$channels are present in cerebral blood vessels. In addition, a number of pharmacological studies using activators and inhibitors have provided functional evidence that $\mathrm{K}^{+}$channels, especially ATP sensitive (Katp) and calcium sensitive (Kca) channels, regulate cerebrovascular tone (18). Prototypical Katp agonists are cromakalim and calcitonin gene related peptide (CGRP), while a Kca agonist is NS 1619. Vasodilation in response to these drugs can be used as an index of the intactness of $\mathrm{K}$ channel function after traumatic brain injury and cerebral ischemia $(2,10)$. Pial artery dilation in response to hypotension is due to activation 
of Katp and Kca channels (3), thereby giving functional significance to intactness of K channel function.

Mitogen activated protein kinase (MAPK), a family of at least 3 kinases, extracellular signal-related kinase (ERK), p38, and c-Jun N-terminal kinase (JNK) is upregulated and may contribute to injury after stroke $(1,21,27)$. This study examined the effect of hypoxia/ ischemia on Katp and Kca induced pial artery dilation and the roles of tPA and ERK MAPK in the modulation of $\mathrm{K}$ channel mediated cerebrovasodilation after injury.

\section{Results}

\section{tPA potentiates hypoxic/ischemic impairment of pial artery dilation in response to Katp and Kca channel agonists}

Cromakalim, CGRP, and NS $1619\left(10^{-8}, 10^{-6}\right)$ elicited reproducible dilation of pial small arteries. Vasodilation in response to all three $\mathrm{K}$ channel agonists was blunted after hypoxia/ ischemia, which was aggravated by pre- and post-injury treatment with tPA ( $2 \mathrm{mg} / \mathrm{kg}$ iv) (Fig 1-3). Pre- and post-injury treatment with EEIIMD (1 mg/kg iv), but not the inactive analogue EEIIMR (1 mg/kg iv), prevented impairment of pial artery dilation in response to cromakalim, CGRP, and NS 1619 (Fig 1-3). Pre-treatment was 30 min prior to whereas post-treatment was $2 \mathrm{~h}$ after injury. Similar observations were made in pial arterioles. This dose of EEIIMD had previously been shown to block dilation to topically applied tPA (7).

\section{The ERK MAPK antagonist U 0126 prevents hypoxic/ischemic impairment of pial artery dilation in response to Katp and Kca channel agonists}

Pre- and post-injury treatment with U $0126(1 \mathrm{mg} / \mathrm{kg}$ iv) prevented impairment of dilation of small pial arteries in response to cromakalim, CGRP, and NS 1619 after hypoxia/ischemia (Fig 1-3). This dose of U 0126 blocked ERK MAPK upregulation after cerebral hypoxia/ ischemia (7). Similar observations were made in pial arterioles. This dose of U 0126 blocked ERK MAPK upregulation after cerebral hypoxia/ischemia $(4,7)$.

\section{Blood chemistry}

Blood chemistry values were collected before and after all experiments. There were no statistical differences between sham control, hypoxia/ischemia, and hypoxia/ischemia antagonist treated animals. Hypoxia decreased $\mathrm{pO}_{2}$ to $35 \pm 4 \mathrm{~mm} \mathrm{Hg}$. Carbon dioxide levels were kept constant during periods of hypoxia. There were no differences in mean arterial blood pressure among groups (Legends for Figures 1-3).

\section{Discussion}

Several new findings emerged from this study. First, pial artery dilation in response to Katp and Kca channel agonists was impaired after cerebral hypoxia/ischemia which was aggravated by tPA administered either pre- or post-injury. Pre- or post-injury administration of EEIIMD, but not the inactive analogue EEIIMR, prevented impairment of $\mathrm{K}$ channel agonist mediated pial artery dilation. Since cerebral autoregulation during hypotension is dependent on intact Katp and Kca function (3), these data suggest that thrombolytic therapy for treatment of CNS ischemic disorders disrupts autoregulation by impairing cationmediated control of cerebrovascular tone.

Second, administration of the ERK MAPK antagonist U 0126 either pre- or post-injury also prevented impairment of Katp and Kca mediated pial artery dilation. Hypoxia/ischemia upregulates ERK MAPK immunoreactivity in cerebral cortex and CSF, in a lipoprotein receptor protein (LRP) dependent manner (4), which was aggravated by tPA administered 
pre- and post-injury (7). Additionally, administration of the LRP antagonist RAP and an anti-LRP antibody blunted impairment of dilation in response to hypercapnia and hypotension after injury (4). Taken together, these data indicate that tPA impairs Katp and Kca mediated cerebrovasodilation through upregulation of ERK MAP in an LRP dependent manner. However, we cannot presently exclude the role of p38 and/or JNK MAPK in modulation of $\mathrm{K}$ channel function. In particular, our recent work indicates that EEIIMD prevents impairment of pial artery dilation in response to hypercapnia and hypotension after cerebral hypoxia/ischemia by augmenting p38 MAPK upregulation (8).

In prior studies, it was observed that ischemia blunted pial artery dilation in response to agonists of the Katp channel but dilation mediated by the Kca channel was resistant to ischemia in the piglet $(7,8)$. Reasons for differences between the present and of the prior studies are uncertain, but could relate to differences in injury outcome between ischemia and hypoxia/ischemia. For example, hypoxia/ischemia blunted pial artery dilation to both Katp and Kca channel agonists whereas ischemia only affected responses to the Katp agonist in a prior preliminary report in the piglet $(2,9,10)$. Results of the present study affirm impairment of dilation in response to agonists of both $\mathrm{K}$ channels after cerebral hypoxia/ischemia.

Control of cerebrovascular tone after hypoxic/ischemic injury plays a critical role in mediating neurologic damage in affected newborns. We found that hypoxia/ischemia impairs dilation of pial arteries in response to hypercapnia and hypotension, while responses to isoproterenol were unchanged $(5,23,27,28)$. Pre-treatment with tPA potentiated the effect of hypoxia/ischemia, reversing hypercapnic and hypotensive pial artery dilation to vasoconstriction (5). This observation is particularly intriguing in that exogenous tPA by itself produced modest dilation in control animals $(5,6)$. Thus, application of a vasodilator would have been predicted to have an additive or synergistic effect in the presence of a second dilator, rather than causing vasoconstriction. Since responses to isoproterenol after hypoxia/ischemia remained unchanged in the presence of the plasminogen activator, these data indicate that this effect is specific for hypercapnia and hypotension and likely depends on the signal transduction cascades that they activate.

The PAI-1 derived peptide EEIIMD inhibits vasoactivity of tPA without inhibiting its fibrinolytic activity $(6,31)$. Pretreatment with EEIIMD partially prevented impairment of hypercapnic and hypotensive pial artery dilation after hypoxia/ischemia $(5,8)$. The protective effect of EEIIMD, however, did not result from a general nonspecific potentiation/inhibition of vascular responsiveness, as it had no effect on dilation induced by isoproterenol $(5,8)$. Results of the present study extend these initial observations and indicate that EEIIMD can be administered in a clinically relevant timeframe to preserve autoregulation post injury.

In conclusion, these data indicate that hypoxia/ischemia impairs $\mathrm{K}$ channel mediated cerebrovasodilation. tPA augments loss of $\mathrm{K}$ channel function after injury by upregulating ERK. These data suggest that thrombolytic therapy for treatment of CNS ischemic disorders can dysregulate cerebrohemodynamics by impairing cation-mediated control of cerebrovascular tone.

\section{Experimental Procedure}

\section{Closed cranial window technique and cerebral hypoxia/ischemia}

Newborn pigs (1-5 days, 1.1-1.5 Kg) of either sex were studied. All protocols were approved by the Institutional Animal Care and Use Committee. Animals were sedated with isoflurane (1-2 MAC). Anesthesia was maintained with a-chloralose $(30-50 \mathrm{mg} / \mathrm{kg}$. supplemented with $5 \mathrm{mg} / \mathrm{kg} / \mathrm{h}$ i.v.). A catheter was inserted into a femoral artery to monitor blood pressure and to sample for blood gas tensions and $\mathrm{pH}$. Drugs to maintain anesthesia 
were administered through a second catheter placed in a femoral vein. The trachea was cannulated, and the animals were ventilated with room air. A heating pad was used to maintain the animals at $37^{\circ}-39^{\circ} \mathrm{C}$, monitored rectally.

A cranial window was placed in the parietal skull of these anesthetized animals. This window consisted of three parts: a stainless steel ring, a circular glass coverslip, and three ports consisting of 17-gauge hypodermic needles attached to three precut holes in the stainless steel ring. For placement, the dura was cut and retracted over the cut bone edge. The cranial window was placed in the opening and cemented in place with dental acrylic. The volume under the window was filled with a solution, similar to CSF, of the following composition (in $\mathrm{mM}$ ): $3.0 \mathrm{KCl}, 1.5 \mathrm{MgCl}_{2}, 1.5 \mathrm{CaCl}_{2}, 132 \mathrm{NaCl}, 6.6$ urea, 3.7 dextrose, and 24.6 $\mathrm{NaHCO}_{3}$. This artificial CSF was warmed to $37^{\circ} \mathrm{C}$ and had the following chemistry: $\mathrm{pH} 7.33, \mathrm{pCO}_{2} 46 \mathrm{~mm} \mathrm{Hg}$, and $\mathrm{pO}_{2} 43 \mathrm{~mm} \mathrm{Hg}$, which was similar to that of endogenous CSF. Pial arterial vessel diameter was measured with a microscope, a camera, a video output screen and a video microscaler.

Total cerebral ischemia was accomplished by infusing artificial CSF into a hollow bolt in the cranium to maintain an intracranial pressure $15 \mathrm{~mm} \mathrm{Hg}$ greater than the numerical mean of systolic and diastolic arterial blood pressure $(28,29)$. Intracranial pressure was monitored via a sidearm of the cranial window. To prevent the arterial pressure from rising inordinately (Cushing response), venous blood was withdrawn as necessary to maintain mean arterial blood pressure no greater than $100 \mathrm{~mm} \mathrm{Hg}$. As the cerebral ischemic response subsided, the shed blood was returned to the animal. Cerebral ischemia was maintained for $20 \mathrm{~min}$. Hypoxia ( $\mathrm{P}_{\mathrm{O} 2}$ of approximately $35 \mathrm{~mm} \mathrm{Hg}$ ) was produced for $10 \mathrm{~min}$ before ischemia by decreasing the inspired $\mathrm{O}_{2}$ via inhalation of $\mathrm{N}_{2}$, which was followed immediately by the total cerebral ischemia.

\section{Protocol}

Two types of pial vessels, small arteries (resting diameter, 120-160 $\mu \mathrm{m}$ ) and arterioles (resting diameter, 50-70 $\mu \mathrm{m}$ ) were examined to determine whether segmental differences in the effects of hypoxia/ischemia could be identified. Typically, 2-3 ml of artificial CSF were flushed through the window over a 30s period, and excess CSF was allowed to run off through one of the needle ports.

Eleven experimental groups were studied (all $\mathrm{n}=5$ ): (1) sham control, vehicle treated, (2) hypoxia/ischemia, vehicle pre-treated, (3) hypoxia/ischemia pre-treated with tPA ( $2 \mathrm{mg} / \mathrm{kg}$ iv), (4) hypoxia/ischemia pre-treated with EEIIMD (1 mg/kg iv), (5) hypoxia/ischemia pretreated with EEIIMR (1 mg/kg iv), (6) hypoxia/ischemia pre-treated with U $0126(1 \mathrm{mg} / \mathrm{kg}$ iv), (7) hypoxia/ischemia, vehicle post-treated, (8) hypoxia/ischemia post-treated with tPA, (9) hypoxia/ischemia post-treated with EEIIMD, (10) hypoxia/ischemia post-treated with EEIIMR, and (11) hypoxia/ischemia post-treated with U 0126. The vehicle for all agents was $0.9 \%$ saline, except for the MAPK inhibitor, which was diluted in dimethyl sulfoxide $(100 \mu \mathrm{l})$ diluted with $9.9 \mathrm{ml} 0.9 \%$ saline. In sham control animals, responses to cromakalim, CGRP, and NS $1619\left(10^{-8}, 10^{-6} \mathrm{M}\right)$ were obtained initially and then again $2.5 \mathrm{~h}$ later in the presence of the agent vehicle. In hypoxia/ischemia animals, responses to vasoactive stimuli were obtained initially and then again $2.5 \mathrm{~h}$ post insult in the presence of the agent vehicle. In drug treated hypoxia/ischemia animals, drugs were administered either 30 min before or $2 \mathrm{~h}$ after hypoxia/ischemia and the insult protocol followed as described above.

\section{Statistical analysis}

Pial artery diameters were analyzed using ANOVA for repeated measures. If the value was significant, the data were then analyzed by Fishers protected least significant difference test. 
An $\alpha$ level of $p<0.05$ was considered significant in all statistical tests. Values are represented as mean \pm SEM of the absolute value or as percentage changes from control value.

\section{Research Highlights}

- Cerebral hypoxia/ischemia impairs both Katp and Kca-mediated cerebrovasodilation

- ERK was upregulated after hypoxia/ischemia, which was potentiated by tPA

- tPA augments loss of $\mathrm{K}$ channel function after injury by upregulating ERK

- Thrombolytic therapy impairs cerebral hemodynamics by impairing $\mathrm{K}$ channel function

\section{Acknowledgments}

This research was funded by grants from the National Institutes of Health, NS53410 and HD57355 (WMA), HL76406, CA83121, HL76206, HL07971, and HL81864 (DBC), HL77760 and HL82545 (AARH), the University of Pennsylvania Research Foundation (WMA), the University of Pennsylvania Institute for Translational Medicine and Therapeutics (DBC), and the Israeli Science Foundation (AARH).

\section{References}

1. Alessandrini A, Namura S, Moskowitz MA, Bonventre JV. MEK1 protein kinase inhibition protects against damage resulting from focal cerebral ischemia. Proc Nat Acad Sci 1999;96:12866-12869. [PubMed: 10536014]

2. Armstead WM. Brain injury impairs ATP-sensitive $\mathrm{K}^{+}$channel function in piglet cerebral arteries. Stroke 1997;28:2273-2280. [PubMed: 9368576]

3. Armstead WM. Hypotension dilates pial arteries by $\mathrm{K}_{\mathrm{ATP}}$ and $\mathrm{K}_{\mathrm{ca}}$ channel activation. Brain Res 1999;816:158-164. [PubMed: 9878717]

4. Armstead WM, Cines DB, Bdeir K, Kulikovskaya I, Stein SC, Higazi AAR. uPA impairs cerebrovasodilation after hypoxia/ischemia through LRP and ERK MAPK. Brain Res 2008;1231:121-131. [PubMed: 18656457]

5. Armstead WM, Cines DB, Higazi AA. Plasminogen activators contribute to impairment of hypercapnic and hypotensive cerebrovasodilation after cerebral hypoxia/ischemia in the newborn pig. Stroke 2005;36:2265-2269. [PubMed: 16141421]

6. Armstead WM, Cines DB, Higazi AA. Plasminogen activators contribute to age dependent impairment of NMDA cerebrovasodilation after brain injury. Dev Brain Res 2005;156:139-146. [PubMed: 16099300]

7. Armstead WM, Ganguly K, Kiessling JW, Chen XH, Smith DH, Higazi AAR, Cines DB, Bdeir K, Zaitsev S, Muzykantov VR. RBC-coupled tPA prevents impairment of cerebral vasodilatory responses and tissue injury in pediatric cerebral hypoxia ischemia through inhibition of ERK MAPK. J Cereb Blood Flow Metab 2009;29:1463-1474. [PubMed: 19436314]

8. Armstead WM, Riley J, Kiessling JW, Cines DB, Higazi AAR. PAI-1-derived peptide EEIIMD prevents impairment of cerebrovasodilation by augmenting p38 MAPK upregulation after cerebral hypoxia/ischemia. AJP 2010;299:H76-H80.

9. Bari F, Louis T, Busjia DW. Calcium-activated K channels in cerebral arterioles in piglets are resistant to ischemia. J. Cereb Blood Flow Metab 1997;17:1152-1156. [PubMed: 9390646]

10. Bari F, Louis T, Meng W, Busija DW. Global ischemia impairs ATP-sensitive K channel function in cerebral arterioles in piglets. Stroke 1996;27:1874-1881. [PubMed: 8841347]

11. Bdeir K, Murciano JC, Tomaszewski J, Koniaris L, Martinez J, Cines DB, Muzykantov VR, Higazi AA. Uorkinase mediates fibrinolysis in the pulmonary microvasculature. Blood 2000;96:1820-1826. [PubMed: 10961882] 
12. Ben-Haim G, Armstead WM. Role of cAMP and K channel-dependent mechanisms in piglet hypoxic/ischemic impaired nociceptin/orphanin FQ-induced cerebrovasodilation. Brain Res 2000;884:51-58. [PubMed: 11082486]

13. Benedict SL, Ni OK, Schloesser P, White KS, Bale JF. Intra-arterial thrombolysis in a 2-year old with cardioembolic stroke. J Child Neurol 2007;22:225-227. [PubMed: 17621489]

14. Bu G, Williams S, Strickland DR, Schwartz AL. Low density lipoprotein receptor-related protein/ alpha 2-macroglobulin receptor is an hepatic receptor for tissue-type plasminogen activator. Proc Nat Acad Sci 1992;89:7427-7431. [PubMed: 1502154]

15. Collen D, Lijnen HR. Basic and clinical aspects of fibrinolysis and thrombolysis. Blood 1991;78:3114-3124. [PubMed: 1742478]

16. Cremer S, Berliner Y, Warren D, Jones A. Successful treatment of pediatric stroke with recombinant tissue plasminogen activator (rt-PA): a case report and review of the literature. CJEM 2008;10:575-578. [PubMed: 19000355]

17. DeVeber G, Andrew M. Cerebral sinovenous thrombosis in children. N Engl J Med 2001;345:417423. [PubMed: 11496852]

18. Faraci FM, Heistad DD. Regulation of the cerebral circulation: role of endothelium and potassium channels. Physiol Rev 1998;78:53-97. [PubMed: 9457169]

19. Ferriero DM. Neonatal brain injury. New Engl J Med 2004;351:1985-1995. [PubMed: 15525724]

20. Gunther G, Junker R, Strater R, Schobess R, Kurnik K, Kosch A, Nowak-Gottl U. Symptomatic ischemic stroke in full-term neonates. Stroke 2000;31:2437-2441. [PubMed: 11022077]

21. Hayashi T, Sakai K, Sasaki C, Zhang WR, Warita H, Abe K. c-JUN N-terminal kinase (JNK) and JNK interacting protein response in rat brain after transient middle cerebral artery occlusion. Neuroscience Lett 2000;284:195-199.

22. Higazi AA, Bdeir K, Hiss E, Arad S, Kuo A, Barghouti I, Cines DB. Lysis of plasma clots by urokinase-soluble urokinase receptor complexes. Blood 1998;92:2075-2083. [PubMed: 9731065]

23. Jagolino AL, Armstead WM. PTK MAPK, and NOC/oFQ impair hypercapnic cerebrovasodilation after hypoxia/ischemia. Am J Physiol 2003;284:H101-H107.

24. Janjua N, Nasar A, Lynch JK, Qureshi AI. Thrombolysis for ischemic stroke in children. Data from the nationwide inpatient sample. Stroke 2007;38:1850-1854. [PubMed: 17431210]

25. Kim YH, Park JH, Hong SH, Koh JY. Nonproteolytic neuroprotection by human recombinant tissue plasminogen activator. Science 1999;284:647-50. [PubMed: 10213688]

26. Kraus FT, Acheen VI. Fetal thrombotic vasculopathy in the placenta: cerebral thrombi and infarcts, coagulopathies, and cerebral palsy. Hum Pathol 1999;30:759-769. [PubMed: 10414494]

27. Laher I, Zhang JH. Protein kinase C and cerebral vasospasm. J Cerebral Blood Flow \& Metabolism 2001;21:887-906.

28. Leffler CW, Busija DW, Armstead WM, Mirro R, Beasley DG. Ischemia alters cerebral vascular responses to hypercapnia and acetylcholine in piglets. Pediatr Res 1989;25:180-183. [PubMed: 2919133]

29. Leffler CW, Busija DW, Beasley DG, Armstead WM, Mirro R. Postischemic microvascular cerebral responses to norepinephrine and hypotension in newborn pigs. Stroke 1989;20:541-546. [PubMed: 2929031]

30. Lynch JK, Hirtz DG, DeVeber G, Nelson KB. Report of the National Institute of Neurological Disorders and Stroke workshop on perinatal and childhood stroke. Pediatrics 2002;109:116-123. [PubMed: 11773550]

31. Nassar T, Haj-Yehia A, Akkawi S, Kuo A, Bdeir K, Mazar A, Cines DB, Higazi AA. Binding of urokinase to low density lipoprotein-related receptor (LRP) regulates vascular smooth muscle cell contraction. J Biol Chem 2002;277:40499-40504. [PubMed: 12171938]

32. Nelson KB, Lynch JK. Stroke in newborn infants. Lancet Neurol 2004;3:150-158. [PubMed: 14980530]

33. Nicole O, Docagne F, Ali C, Margaill I, Carmeliet P, MacKenzie ET, Vivien D, Buisson A. The proteolytic activity of tissue-plasminogen activator enhances NMD receptor-mediated signaling. Nature Med 2001;7:59-64. [PubMed: 11135617] 
34. Volpe JJ. Brain injury in the premature infant: overview of clinical aspects, neuropathology, and pathogenesis. Semin Pediatr Neurol 1998;5:135-151. [PubMed: 9777673]

35. Wang YF, Tsirka SE, Strickland S, Stiege P,E, Lipton SA. Tissue plasminogen activator (tPA) increases neuronal damage after focal cerebral ischemia in wild-type and tPA-deficient mice. Nat Med 1998;4:228-231. [PubMed: 9461198] 


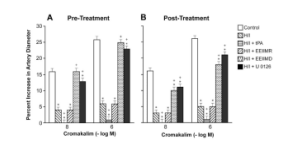

Figure 1.

Influence of cromakalim $\left(10^{-8}, 10^{-6} \mathrm{M}\right)$ on pial artery diameter before injury (control), $2.5 \mathrm{~h}$ after hypoxia/ischemia (H/I), $2.5 \mathrm{~h}$ after H/I treated with $\mathrm{tPA}(2 \mathrm{mg} / \mathrm{kg}$ iv), $2.5 \mathrm{~h}$ after H/I treated with EEIIMR ( $1 \mathrm{mg} / \mathrm{kg}$ iv), $2.5 \mathrm{~h}$ after $\mathrm{H} / \mathrm{I}$ treated with EEIIMD $(1 \mathrm{mg} / \mathrm{kg}$ iv), and $2.5 \mathrm{~h}$ after $\mathrm{H} / \mathrm{I}$ treated with $\mathrm{U} 0126(1 \mathrm{mg} / \mathrm{kg}$ iv), $\mathrm{n}=5$. A: pre-treatment $30 \mathrm{~min}$ prior to $\mathrm{H} / \mathrm{I}$, B: post-treatment $2 \mathrm{~h}$ after $\mathrm{H} / \mathrm{I}$. Baseline pial artery diameters were $138 \pm 14,118 \pm 11,116 \pm$ $10,121 \pm 13$, and $120 \pm 11 \mu \mathrm{m}$ for control, H/I, H/I + tPA, H/I + EEIIMR, H/I + EEIIMD, and $\mathrm{H} / \mathrm{I}+\mathrm{U} 0126$ pretreated respectively. Mean arterial blood pressure was $70 \pm 9,65 \pm 7$, $66 \pm 7,67 \pm 8$ and $68 \pm 9 \mathrm{~mm} \mathrm{Hg}$, respectively, under the same sequence of experimental groups. ${ }^{*} \mathrm{p}<0.05$ compared with corresponding control value ${ }^{+} \mathrm{p}<0.05$ compared with corresponding $\mathrm{H} / \mathrm{I}$ non-treated value. 


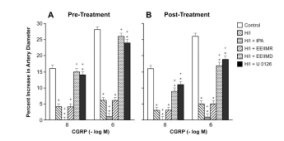

Figure 2.

Influence of calcitonin gene related peptide (CGRP) $\left(10^{-8}, 10^{-6} \mathrm{M}\right)$ on pial artery diameter before injury (control), 2.5h after hypoxia/ischemia (H/I), 2.5h after H/I treated with tPA (2 $\mathrm{mg} / \mathrm{kg}$ iv), $2.5 \mathrm{~h}$ after $\mathrm{H} / \mathrm{I}$ treated with EEIIMR (1 $\mathrm{mg} / \mathrm{kg}$ iv), $2.5 \mathrm{~h}$ after $\mathrm{H} / \mathrm{I}$ treated with EEIIMD (1 mg/kg iv), and 2.5h after H/I treated with $\mathrm{U} 0126$ (1 mg/kg iv), $\mathrm{n}=5$. A: pretreatment $30 \mathrm{~min}$ prior to $\mathrm{H} / \mathrm{I}$, B: post-treatment $2 \mathrm{~h}$ after $\mathrm{H} / \mathrm{I}$. Baseline pial artery diameters were $140 \pm 16,121 \pm 11,117 \pm 10,123 \pm 13$, and $121 \pm 12 \mu \mathrm{m}$ for control, H/I, H/I $+\mathrm{tPA}$, $\mathrm{H} / \mathrm{I}+\mathrm{EEIIMR}, \mathrm{H} / \mathrm{I}+\mathrm{EEIIMD}$, and H/I + U 0126 pretreated respectively. Mean arterial blood pressure was $72 \pm 9,66 \pm 7,65 \pm 7,66 \pm 8$ and $68 \pm 9 \mathrm{~mm} \mathrm{Hg}$, respectively, under the same sequence of experimental groups. $* \mathrm{p}<0.05$ compared with corresponding control value ${ }^{+} \mathrm{p}<0.05$ compared with corresponding $\mathrm{H} / \mathrm{I}$ non-treated value. 


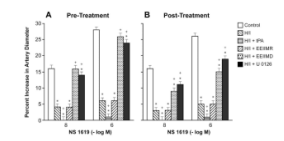

Figure 3.

Influence of NS $1619\left(10^{-8}, 10^{-6} \mathrm{M}\right)$ on pial artery before injury (control), $2.5 \mathrm{~h}$ after hypoxia/ischemia (H/I), 2.5h after H/I treated with tPA $(2 \mathrm{mg} / \mathrm{kg}$ iv), $2.5 \mathrm{~h}$ after H/I treated with EEIIMR ( $1 \mathrm{mg} / \mathrm{kg}$ iv), $2.5 \mathrm{~h}$ after H/I treated with EEIIMD ( $1 \mathrm{mg} / \mathrm{kg}$ iv), and $2.5 \mathrm{~h}$ after $\mathrm{H} / \mathrm{I}$ treated with $\mathrm{U} 0126(1 \mathrm{mg} / \mathrm{kg}$ iv), $\mathrm{n}=5$. A: pre-treatment $30 \mathrm{~min}$ prior to H/I, B: posttreatment $2 \mathrm{~h}$ after $\mathrm{H} / \mathrm{I}$. Baseline pial artery diameters were $136 \pm 13,119 \pm 12,118 \pm 11,120$ \pm 12 , and $118 \pm 11 \mu \mathrm{m}$ for control, H/I, H/I + tPA, H/I + EEIIMR, H/I + EEIIMD, and H/I + U 0126 pretreated respectively. Mean arterial blood pressure was $73 \pm 9,66 \pm 8,66 \pm 7,67$ \pm 8 and $68 \pm 9 \mathrm{~mm} \mathrm{Hg}$, respectively, under the same sequence of experimental groups. ${ }^{*} \mathrm{p}<0.05$ compared with corresponding control value ${ }^{+} \mathrm{p}<0.05$ compared with corresponding $\mathrm{H} / \mathrm{I}$ non-treated value. 